\section{Measuring event experience and its behavioral consequences in the context of a sports mega-event}

Measuring event experience

Annarita Sorrentino

Department of Management and Quantitative Studies, University of Naples-Parthenope, Napoli, Italy Xiaoxiao $\mathrm{Fu}$

Rosen College of Hospitality Management, University of Central Florida, Orlando, Florida, USA

Rosaria Romano

Department of Economics and Statistics, University of Naples Federico II, Naples, Italy

Michele Quintano

University of Naples Parthenope, Naples, Italy and

Department of Marketing, ESADE Business School, Madrid, Spain, and

Marcello Risitano

Department of Management and Quantitative Studies, University of Naples-Parthenope, Napoli, Italy

\begin{abstract}
Purpose - This study aims to analyze the impact of event experience on event satisfaction and intentions to return and recommend the destination.

Design/methodology/approach - Relationships among constructs were tested on data gathered from 542 tourists during the America's Cup World Series held in South Italy in April 2013 by using a structural equation modeling approach. Moreover, a multigroup analysis was developed to test the possible moderator factors.

Findings - The results revealed that event experience and event satisfaction had positive impacts on the intentions to recommend and return to the host destination. Moreover, nationality, gender and trip motivation emerged as important moderating factors in the relationships among the latent constructs.

Research limitations/implications - The findings of this paper enrich the existing literature and help tourism destination marketers and managers consider the triggering factors of a satisfying mega-sports event for the host destination and the marketing power of the on-site experience.

Practical implications - Practitioners should draw on the insights provided by this study to design destination strategies, particularly by paying attention to how an event experience causes an attendee to return to and recommend the host destination.

Originality/value - This study enriches the existing event literature in several ways. First, it emphasizes the importance of the event experience to the satisfaction level and willingness to return and recommend the host destination for a vacation, supporting the link between an event and its destination. Second, it provides a moderating analysis that offers new insights for marketing the event experience. It offers a multilevel model of mega-event tourism legacy, which opens up new avenues of research. Third, complementing the consumer-
\end{abstract}

(C) Annarita Sorrentino, Xiaoxiao Fu, Rosaria Romano, Michele Quintano and Marcello Risitano. Published by Emerald Publishing Limited. This article is published under the Creative Commons Attribution (CCBY 4.0) licence. Anyone may reproduce, distribute, translate and create derivative works of this article (for both commercial and non-commercial purposes), subject to full attribution to the original publication and authors. The full terms of this licence may be seen at http://creativecommons. org/licences/by/4.0/legalcode

The authors thank the Local Organizing Committee (America's Cup Napoli - ACN) for the opportunity to collect data during the event and Campania Region for the access to official data on incoming flows.

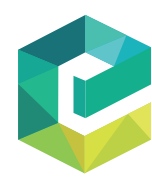

Received 4 March 2020

Revised 22 May 2020

19 June 2020

21 June 2020

Accepted 21 June 2020 
JHTI

3,5 based analysis, this research includes the trend of visits (after 2013 to the present) to examine how a mega-sport event has brought about more postevent visits.

Keywords Sports mega-event, Event experience, Event satisfaction, Behavioral intentions, America's Cup World Series

Paper type Research paper

\section{0}

\section{Introduction}

Tourist destinations host mega-events for various reasons, principally the short-term economic impact of hosting the participants and spectators during the event (Arnegger and Herz, 2016; Knott et al., 2017; Risitano et al., 2017a) and the medium- to long-term benefit of the media exposure (Arnegger and Herz, 2016; Chalip and Fairley, 2019; Müller, 2015). The latter benefits are especially pertinent in the case of international sports mega-events, such as the Olympic Games, the FIFA World Cup and the America's Cup. Such events are often hosted to promote the country in terms of its culture as well as its tourist attractions (Chalip et al., 2003; Getz, 2008; Müller, 2015). Sports mega-events have short-, medium- and long-term economic impacts, improve destination awareness and create new tourist demand. In fact, in the last decade, the sports events industry has grown significantly around the world, with a massive number of events hosted in varied locations. Destinations invest billions of dollars to host mega-sports events in terms of candidacy, media rights and infrastructure construction (Giampiccoli et al., 2015); therefore, it is important to monitor whether the event can truly positively impact tourists' experience and their willingness to recommend or return for a vacation. From this perspective, researchers and practitioners consider the analysis of megaevent tourist behavior critical to evaluating the effects of collective marketing programs by the host destination (Novelli et al., 2006).

To the best of our knowledge, despite the relevance of this phenomenon, most of the previous literature has focused on the effects of destination image on event satisfaction and behavioral intentions to return or recommend a particular event or to revisit the destination for another sports event (Chang et al., 2014; Chen and Funk, 2010; Kaplanidou, 2009; Kaplanidou and Vogt, 2010; Song et al., 2015). However, it is still unclear whether high degrees of satisfaction with a particular event generate positive behavioral intentions for that specific event only, or whether those intentions extend to the destination more generally. In their study of sport tourists' behaviors, Kaplanidou and Vogt (2007) found that satisfaction with a sporting event did not significantly influence intentions to revisit the destination for the general sport tourism activities it could offer, while Kaplanidou and Gibson (2010), investigating small-scale recurring sports events, reported that satisfaction did directly influence intention to attend the event again. Adding to the inconclusive data, due to the destination marketing investments in mega-events, it is also important to understand the weight of the event as a trigging factor for tourist destination development.

Against this backdrop, this paper aims to test the influence of event experience (EE) on intention to recommend (ITREC) and intention to revisit the host destination for future holidays (ITRET), mediated by event satisfaction (ES) during a mega-sports event called the America's Cup World Series. Five hypotheses were formulated to verify the dynamics among the latent constructs, with three additional hypotheses to verify the moderating effects of nationality, gender and trip motivation. Adding to the findings of the structural model, the research includes the trend of visits (after 2013 to the present) in the implications to present how a mega-sports event has brought about more visits afterward. For example, the results showed that incoming flows have almost doubled since the event to date, increasing from $2,166,518$ tourists in 2012 to $3,292,556$ tourists in 2016 to $3,700,000$ in 2019, and the occupancy rate has grown from $42.12 \%$ in 2012 before the event to $64.89 \%$ in 2016 , three years after the event, and to $71.40 \%$ in 2019 . 


\section{Literature review}

The concept of experience has been introduced only recently into studies of event tourism (Kim et al., 2012; Song et al., 2019; Tung and Ritchie, 2011). Ayob et al. (2013) find that visitors' EEs

influence their overall satisfaction, which, in turn, affects their intention to return. Similarly, Chang et al. (2014) demonstrate that on-site experience is the most influential antecedent of the intention to revisit a destination. Caro and García (2007) suggest that consumer satisfaction at sports events is based on cognitive and affective factors. Kaplanidou et al. (2012) demonstrate, in the context of tourist behavior at sports events, that image, satisfaction and behavioral intentions are all positively interrelated. Dos Santos (2012) evaluates two models of tourist behavior at sports events, termed "planned behavior" and "disconfirmation of expectations," and concludes that it is important to match the two approaches and to emphasize the role of emotions in overall satisfaction. In this light, it is of interest that an event is likely to become an "experience" when participation is rich in sensations (as this has been shown generally to generate positive emotions) and can personally engage consumers (Berridge, 2007; Coghlan and Filo, 2016; Lee et al., 2011). Weed (2005) reports that spectators at a sports event who have a positive EE are more likely to attend the event again.

From the more general perspective of marketing research, Brakus et al. (2009) define a model that conceptualizes experience as a consumer response. The model has four main latent subdimensions: sense, feel, think and act. Sense relates to the impact of marketing on the five senses (taste, smell, etc.). Feel relates to affect, that is, the emotional component, and includes memories. Think concerns the cognitive component or thoughts about an experience. Act is perhaps the most important of the subdimensions from a marketing perspective. It is the last step and reflects whether the experience produces action. In the present context, the action might be a purchase, a recommendation or a return to an event or destination. The model proposed by Brakus et al. is well suited to the study of $\mathrm{EE}$, as attendance at an event involves just such a set of sensory and emotional elements (Ayob et al., 2013). In recent research (Song et al., 2015), the five experience dimensions from Brakus et al. (2009) are employed in an empirical study on mega-events that show a positive impact on visitor satisfaction mediated by emotions (pleasure, arousal and dominance). The relationship between the spectators' $\mathrm{EE}$ and satisfaction also affects visitors' intentions regarding future events (Ayob et al., 2013). Hence, overall satisfaction can be considered a mediator between $\mathrm{EE}$ and future intentions.

\section{Event satisfaction and behavioral intentions}

In the marketing literature, the construct of satisfaction is usually measured using a model of expectation/disconfirmation (Dos Santos et al., 2019; Huang, 2017). In the tourism literature, either a multi-item scale is usually used to measure this construct (Ali et al., 2016; Kozak, 2003; Huang, 2017) or a single item is used to measure overall satisfaction (Del Bosque and Martín, 2008). A positive EE can have a direct impact on tourist satisfaction (Lee et al., 2011; Song et al., 2019) and behavioral intentions (Brown et al., 2016; Hui et al., 2007). Ayob et al. (2013) emphasize that a positive EE is associated with overall satisfaction as well as with positive intentional behavior.

According to the general literature on marketing, tourism and hospitality (Bigne et al., 2001; Kim et al., 2017; Yang et al., 2014), it is assumed that tourist spectators who have a positive overall experience will convey positive word-of-mouth. More specifically, they will have an intention to recommend (ITREC) an event or destination and will intend to return to the event or destination (ITRET). The sport and tourism literature in general confirms that tourist satisfaction and behavioral intention are positively related (Bigne et al., 2001; Kaplanidou and Gibson, 2010; Prayag and Grivel, 2014). However, it is unclear whether satisfaction with an event leads to positive behavioral intentions for the event only, the destination or both. Kaplanidou and Vogt (2007) find that satisfaction with an event does not 
JHTI 3,5

592

significantly influence intentions to revisit the destination, while Kaplanidou and Gibson (2010) show that satisfaction with an event directly influences intentions to participate in the event again. Therefore, this study examines the following research hypotheses (see Figure 1):

H1. EE is positively related to ES.

H2. EE will positively affect ITREC.

H3. EE will positively affect ITRET.

H4. ES will positively affect ITREC.

H5. ES will positively affect ITRET.

In addition, trip motivation, nationality and gender have been considered as potential moderators among latent constructs. Trip motivation plays an important role in the events' context because it can influence tourist perceptions. Chen and Funk (2010) distinguish between participants and spectators based on travel motivation, by defining event participants as individuals who participate in an organized competitive or noncompetitive sports event, while event spectators are those whose main purpose of travel is to watch the event. The same authors highlight that the two different niche markets have different behaviors and different destination perceptions. Accordingly, we formulate the following hypothesis:

H6a. Trip motivation moderates the relationships among the latent constructs.

Moreover, previous studies on consumer behavior show different perceptions, attitudes and behaviors between males and females (Chalip et al., 2003; Okazaki and Mendez, 2013; Jones et al., 2017). Specifically, gender has been recognized as a variable that influences consumer

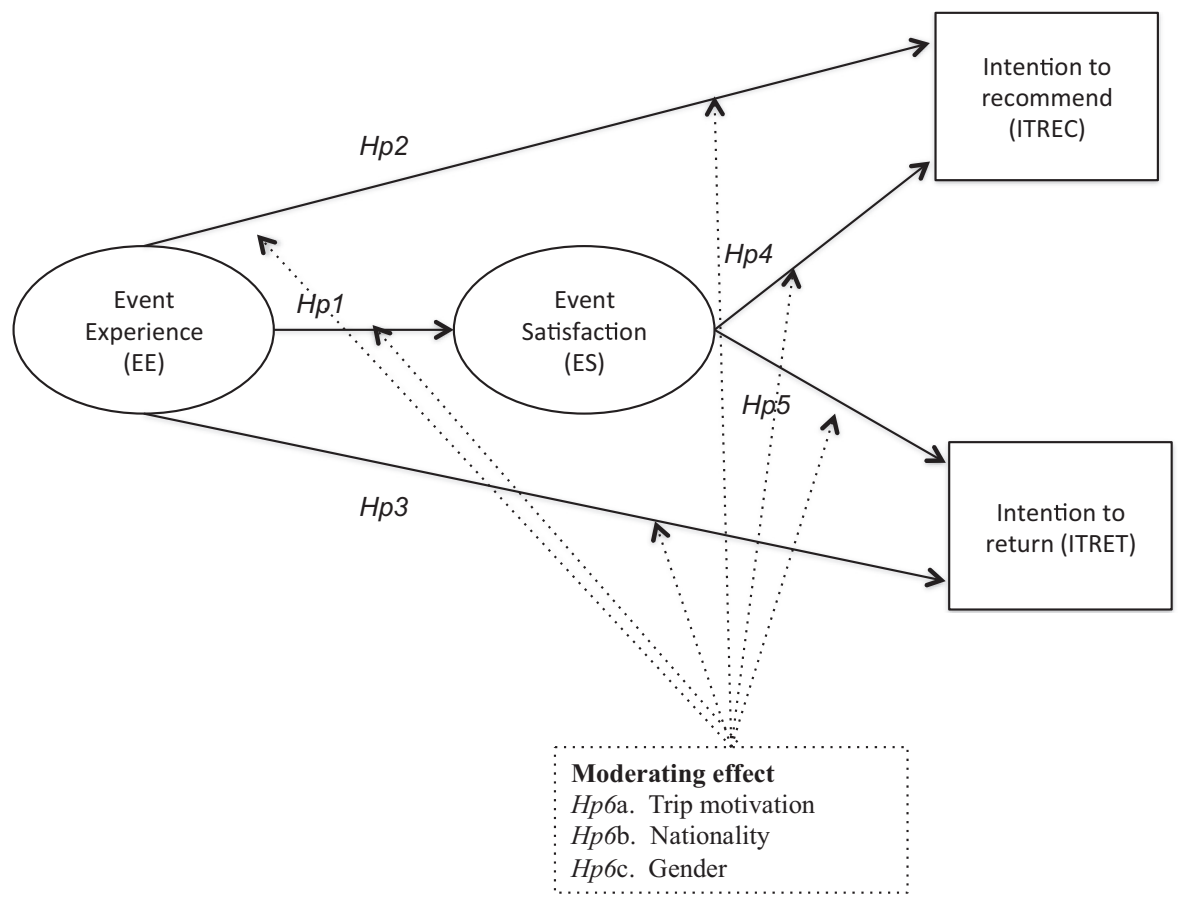

Figure 1.

The conceptual framework
Moderating effect

Hp6b. Nationality

Hp6c. Gender 
decision-making (Hansen and Møller Jensen, 2009; Chiu et al., 2005). In sports mega-events, gender differences have been analyzed for volunteering activities (Downward et al., 2005), but never as a moderator in the behavioral models. Accordingly, we hypothesize that gender influences the relationships among the latent constructs:

Measuring event experience

$H 6 b$. Gender moderates the relationships among the constructs.

Nationality is a relevant sociodemographic variable affecting consumer decision-making (Kotler and Keller, 2001). In the tourism context, nationality has been mainly explored as a moderator in the destination decision-making process (Nicolau and Màs, 2006; Yang, et al., 2018) or as a proxy for cultural background (Hofstede, 1980; Lucey and Zhang, 2010; Ng et al., 2007). In the field of events, previous studies (Alcántara-Pilar et al., 2017; Crotts, 2004; Risitano et al., 2017b; Kim and McKercher, 2011) confirm that national culture affects behavioral intentions regarding a specific destination, but no study has used nationality as a moderating variable between event experience and behavioral intentions. Accordingly, in this study, nationality is considered a moderator in the relationships among perceived event experience, satisfaction and behavioral intentions. The following hypothesis is made:

H6c. Nationality moderates the relationships among the constructs.

\section{Methods \\ Study site: America's Cup World Series (ACWS)}

The ACWS is the most important sailing mega-event in the world. It consists of a circuit of regattas organized in three main events: the Louis Vuitton Cup, the America's Cup Challenger Series and the America's Cup Finals. From a theoretical perspective, it is a study of interest because it represents an event similar to the Olympic Games or the EXPO, with a low level of frequency and a high level of complexity (Getz, 2008). In addition, on the marketing side, the event represents a strategic marketing opportunity for worldwide promotion of the host destination. Moreover, the ACWS has been part of a wider destination repositioning strategy of the local area (Naples, Italy) through the reinforcement of the local area's many strengths: food, music, culture, art and friendly people. The Parthenope University of Naples was the official scientific partner of the event, according to the local organizing committee called America's Cup Naples (ACN). The latter provided a stand and survey facilities for the volunteers employed for the survey.

\section{Data collection}

The data were gathered through an on-site survey during the ACWS in Naples in 2013. A structured questionnaire was administered by 50 trained university students to a sample of Italian and foreign tourists in the Event Public Village during the regatta days (April 18 to April 21, 2013). Only tourists who had already experienced the event were interviewed. An equal interval timing method was used by the interviewers to obtain the sample. That is, at every $15 \mathrm{~min}$, interviewers approached a tourist and asked if she or he would agree to an onsite interview. The first version of the questionnaire was sent to the ACN department to assess the validity of the items; it was then disseminated during the local opening event at the beginning of April 2013 to identify and eliminate errors and to ensure the clarity of the question wording, but, in fact, minimal change was made. The questionnaire was presented in both English and Italian versions, and both were tested during the preliminary stage. The initial sample totaled 612 questionnaires; after the removal of those that were incomplete or on which the majority of the items were given average scores or scores at either end of the Likert scale, the analysis was based on 542 sets of responses. 

JHTI

594

\section{Measures}

To assess the theoretical model, the constructs of $\mathrm{EE}$ and $\mathrm{ES}$ were considered as second-order constructs, while intentional behaviors were measured through two single items: ITREC and ITRET. In particular, EE was measured using a shortened version of the Brand Experience Scale (Zarantonello et al., 2007) with 12 items that included three items for each subdimension illustrated in the theoretical paragraph (sense, feel, think, act). To measure the construct of satisfaction, a multi-item scale was adapted from the existing literature (Bigne et al., 2001; Kozak, 2003). The construct of ES was considered as a second-order construct divided into two subdimensions: (1) regatta-related factors (RRF) and (2) village-related factors (VRF), according to the ACN as synthesized by the ACWS's value proposition. Finally, the behavioral intentions were measured by the ITREC and ITRET to the destination. A fivepoint Likert scale was adopted to measure all the factors referring to $\mathrm{EE}$ and behavioral intentions ( 1 = strongly disagree; $5=$ strongly agree), while ES was simply measured as the level of satisfaction with the items $(1=$ very dissatisfied; $5=$ very satisfied $)$.

\section{Data analysis}

We employed structural equation modeling (SEM) to assess the causal effects of the latent variables. The partial least squares approach to SEM (PLS-SEM) (Ali et al., 2018; Wold, 1985) was used as a suitable alternative to the classical covariance-based (CB) SEM (CB-SEM) (Ali et al., 2018; Jöreskog, 1978). PLS-SEM is a flexible approach in modeling various phenomena in socioeconomic disciplines that could not be modeled otherwise because of violations of the strict assumptions of traditional CB-SEM.

\section{Results}

Demographic profile

The sample of 542 respondents consisted of approximately $60 \%$ males $(n=326)$. Most of them were Italians $(n=330,61 \%)$, and few were over 55 years old $(n=68,13 \%)$. Approximately $53 \%$ of the respondents $(n=288)$ declared a daily average expenditure of less than 100 euros, while the remainder $(n=254,47 \%)$ declared a higher daily expenditure. Half of the survey sample $(n=271)$ indicated the ACWS sports event as the main motivation for their trip, while the other half declared other reasons (e.g., culture, nature, wellness, business). Approximately $56 \%$ of the respondents $(n=301)$ appeared to be curious about the event, $23 \%$ were passionate about sailing $(n=162)$ and the remainder $(n=79)$ did not fit in either of the two previous profiles.

\section{Analysis of the measurement model}

The two-step procedure was used because the proposed model also includes second-order constructs (Wetzels et al., 2009). The first step of this procedure consists of calculating the latent variable scores of the first-order constructs, while the second step of the procedure uses the obtained latent variable scores as items to measure the second-order constructs.

Two separate hierarchical PLS models were estimated to obtain the latent variable scores of the two second-order constructs considered in this study: (1) a model that relates the ES construct with its two first-order constructs, RRF and VRF, and (2) a model that relates the ES construct with its four first-order constructs (sense, feel, think, act). The EE construct is composed of an almost equitable contribution from the four subscales (SENSE $=0.319$, FEEL $=0.313$, THINK $=0.306$, ACT $=0.282$ ), while the VRF construct dominates $(\mathrm{VRF}=0.913)$ the $\mathrm{RRF}$ construct $(\mathrm{RRF}=0.246)$ in generating the ES construct.

We proceeded to estimate the model described in the conceptual framework once the latent variable scores of the six first-order constructs were obtained (see Figure 1). Table 1 shows 
that all the standardized item loadings were greater than the minimum threshold of 0.7 , and this confirms individual reliability. Furthermore, the composite reliability of each construct in the model was confirmed, as the composite reliability (CR) index of each was over the benchmark value of 0.7 suggested by Nunnally and Bernestein (1994). The constructs also fulfilled the criteria for convergent validity, as the values of average extracted variance (AVE) were higher than 0.50 . Such a result indicates that constructs can explain more than half of the variance of their indicators on average, that is, the set of indicators of each construct represents the same underlying construct.

Table 2 shows the assessment of discriminant validity by the criterion of Barclay et al. (1995). That is, the square root of AVE (shown in italic in Table 2) from each construct was greater than the inter-construct correlation. This indicates that each construct was unique and truly distinct from the other constructs.

\section{Analysis of the structural model}

The results of the structural model are shown in Table 3 . We estimated the significance of the PLS parameter estimates (path coefficient) using a bootstrap procedure. Since PLS-SEM does not reset any distributional assumption, a nonparametric approach is used to estimate the precision of the estimates. Specifically, in bootstrapping, the sampling distribution of a statistic is constructed empirically by resampling from the sample. Based on this distribution, it is possible to determine the standard error of the estimated coefficients that can be used to construct confidence intervals. The quantiles of the bootstrap sampling distribution can be used to calculate the endpoints of a confidence interval non-parametrically. The lower and upper percentiles of the $95 \%$ bootstrap confidence interval showed that all the path coefficients were significant at a 5\% confidence level, as zero did not fall within the confidence intervals. The EE significantly influenced the ES (path = 0.500), that is, the hypothesis that the true value in the population equals zero was rejected, thus validating H1. The ES was the strongest predictor of ITRET (path $=0.214$ ), followed by EE $($ path $=0.125)$. These results

\begin{tabular}{llccccc}
\hline $\begin{array}{l}\text { Latent } \\
\text { variable }\end{array}$ & Items & $\begin{array}{c}\text { Standardized } \\
\text { loadings }\end{array}$ & $\begin{array}{c}\text { Lower bound } \\
(95 \%)\end{array}$ & $\begin{array}{c}\text { Upper bound } \\
(95 \%)\end{array}$ & CR & AVE \\
\hline EE & SENSE & 0.850 & 0.814 & 0.881 & 0.891 & 0.670 \\
& FEEL & 0.862 & 0.840 & 0.891 & & \\
& THINK & 0.811 & 0.752 & 0.850 & & \\
ES & ACT & 0.746 & 0.679 & 0.788 & & 0.764 \\
& RRF & 0.835 & 0.776 & 0.893 & & 0.617 \\
ITRET & VRF & 0.733 & 0.626 & 1 & 1 & 1 \\
ITREC & ITRET & 1 & 1 & 1 & 1 & 1
\end{tabular}

Note(s): The ITRET and ITREC constructs present values all equal to one as they are single-item constructs

Measuring event experience

595

\begin{tabular}{|c|c|c|c|c|c|}
\hline & $\mathrm{EE}$ & $\mathrm{ES}$ & ITRET & ITREC & \\
\hline $\mathrm{EE}$ & 0.819 & & & & \\
\hline $\mathrm{ES}$ & 0.500 & 0.785 & & & $\begin{array}{l}1 \text { able } 2 . \\
\text { Inter-construct }\end{array}$ \\
\hline ITRET & 0.232 & 0.277 & 1.000 & & correlation values and \\
\hline ITREC & 0.270 & 0.307 & 0.545 & 1.000 & the square root of AVE: \\
\hline \multicolumn{5}{|c|}{ Note(s): The square root of AVE is displayed on the diagonal } & discriminant validity \\
\hline
\end{tabular}


JHTI 3,5

596 validate $\mathrm{H} 2$ and $\mathrm{H} 3$. We observed a similar pattern in the prediction of ITREC; ES had a greater impact (path $=0.230$ ) than $\mathrm{EE}$ ( ath $=0.155$ ). This result supports $\mathrm{H} 4$ and H5. Table 4 also shows the coefficients of determination $\left(R^{2}\right)$ for each endogenous construct, indicating the amount of variance in the endogenous construct explained by the constructs linked to it. The highest $R^{2}$ was found for the ES construct $\left(R^{2}=0.25\right)$, while for ITREC and ITRET, the values were lower ( 0.11 and 0.09 , respectively). It was not easy to define acceptable values for this index because they greatly depend on the research discipline. Although value of $R^{2}=0.20$ is considered high in disciplines such as consumer behavior, in other disciplines, researchers expect higher values (Hair et al., 2016). Moreover, low $R^{2}$ values could be due to heterogeneity of observations. In fact, from the analysis of the moderating effect proposed in the following sections, it is clear that for some subgroups of observations, the goodness of fit of the model improved considerably. For example, in the case of nationality (see Table 4), the model estimated for foreigners showed higher $R^{2}$ values, especially for the ES construct (0.42). Similar results were also found for the women's subgroup (see Table 4).

\section{Testing moderator effects}

We further tested the mediator effects using the multigroup procedure because the moderator variables considered in this study are qualitative (i.e., categorical) (Sarstedt et al., 2011). The permutation test (Dibbern and Chin, 2010) was used to determine whether the observed difference between the path coefficients was sufficient to reject the null hypothesis, $\mathrm{H} 0$, or whether the two groups could be considered to be identical.

Table 4 shows the results of the moderator effects analysis. Particularly, motivation moderated the influence of EE on ES; the path coefficients between the two differently motivated groups of tourists significantly differed at the $10 \%$ level. EE had a slightly greater effect on ES for tourists who had embarked on the trip for reasons not strictly related to the sports event. Nationality had a moderator effect on the relationship between ES and EE ( $p$ value $=0.010$ ). The positive experience of the event increased ES even more for foreign tourists (path $=0.645$ ) than for Italians ( ath $=0.417$ ). Gender also had a moderator effect on the relationship between EE and ITRET ( $p$-value $=0.040)$ and that between ES and ITRET $(p$ value $=0.010$ ). For male tourists, the EE had a greater effect on the intention to return to the tourist area (path $=0.207$ ). For female tourists, ES was the dominant driver (path $=0.354$ ) for a possible return to the place.

\section{Discussion}

This study contributes to the knowledge of tourist behavior at a destination while attending a sports mega-event by analyzing the effects of $\mathrm{EE}$ on the intentions to recommend and return to the host destination for a holiday through the mediating role of ES. Specifically, it was revealed that the experiential response in the context of a sports mega-event is an important predictor of perceived satisfaction. Moreover, our findings revealed that both EE and ES

\begin{tabular}{|c|c|c|c|c|c|c|}
\hline Causal relations & Hypothesis & Result & Path & $\begin{array}{c}\text { Lower bound } \\
95 \%\end{array}$ & $\begin{array}{c}\text { Upper bound } \\
95 \%\end{array}$ & $R^{2}$ \\
\hline $\mathrm{EE} \rightarrow \mathrm{ES}$ & $\mathrm{H} 1(+)$ & Supported & 0.500 & 0.438 & 0.558 & 0.25 \\
\hline $\mathrm{EE} \rightarrow \mathrm{ITRET}$ & $\mathrm{H} 2(+)$ & Supported & 0.125 & 0.032 & 0.215 & 0.09 \\
\hline $\mathrm{ES} \rightarrow$ ITRET & $\mathrm{H} 3(+)$ & Supported & 0.214 & 0.127 & 0.274 & \\
\hline $\mathrm{EE} \rightarrow \mathrm{ITREC}$ & $\mathrm{H} 4(+)$ & Supported & 0.155 & 0.058 & 0.252 & 0.11 \\
\hline $\mathrm{ES} \rightarrow \mathrm{ITREC}$ & H5 (+) & Supported & 0.230 & 0.152 & 0.301 & \\
\hline
\end{tabular}

Table 3.

Results of the structural model 
JHTI

3,5

598

influence word-of-mouth and the intention to return to the destination. Trip motivation, nationality and gender were important moderating variables for improving our understanding of the heterogeneity of tourist behaviors.

This study tested five hypotheses to verify the relationships among EE, ES and behavioral intentions in the context of a sports mega-event. Due to the missed unidimensionality of EE and ES, the preliminary results of the second-order analysis show the main elements affecting event experience and satisfaction. In particular, the experience was mostly affected by sensitive and feeling elements. This result was confirmed by the fact that the event was not designed to engage visitors in practical activities but to offer an aesthetic and entertainment experience (Kim et al., 2012). The event design was mainly based on the natural landscape as the venue for the regatta event and an eventscape created by the event village (Yang et al., 2014). In addition, people were satisfied by the VRF more than the $\mathrm{RRF}$, demonstrated by the fact that people found the "artificial" environment (e.g., entertainment, exhibitions, food service) created by the event organizer extraordinarily engaging (Ayob et al., 2013; Chang et al., 2014).

A key objective of the study was to examine the relationships among event experience, satisfaction and intentions to recommend and revisit the host destination. These relationships were all supported in the global model by confirming the five hypotheses. Previous studies on the topic demonstrated a negative relationship between event satisfaction and willingness to revisit the destination (Kaplannidou and Vogt, 2007; Brown et al., 2016), explained by the fact that visitors were primary spectators interested only in the event (Chen and Funk, 2010). The present study offers a disconfirmation of these previous results by showing a positive link between event and destination, which could be justified by the fact that most of the people (see Table 2) were merely curious to see the event and not professional sailors or ACWS fans. These findings suggest that the destination captured their attention effectively by influencing their decisions regarding a future visit and positive word of mouth.

In addition, the multigroup analysis revealed moderating variables that can be used to orient marketing strategies to specific clusters. Nationality as a variable highlighted the heterogeneity among tourists in the relationship between $\mathrm{EE}$ and event satisfaction. In particular, foreign tourists were more satisfied with the event and more willing to return than Italian tourists. Although further analysis is needed to conduct a more specific national-based analysis (Hofstede, 2001), this finding is consistent with other studies examining the relationship between event satisfaction and revisit intentions (Brown et al., 2016; Kaplanidou, 2009), where geographic proximity is considered one of the determining moderating factors affecting tourist behavior (Chand and Kumar, 2017; Pizam and Sussman, 1995).

Moreover, as sailing is generally considered a more male-oriented sport, the difference in gender perceptions is clearer in this study. In particular, men were more willing than women to recommend revisiting the destination because they had a more positive EE. This result could be explained by the motivation for attending the event. Men who had the event as their primary motivation probably appreciated the destination, but as they had less time to visit it, they may have a greater desire to return. Finally, motivation was also an important finding. People who were primarily motivated to visit the destination because they were attending the event were less satisfied than those who were at the destination for reasons other than the event (i.e., cultural and/or wellness tourism and business). This result may reflect the different levels of expectations among these tourists. In particular, ACWS tourists may have had higher expectations that were disconfirmed by the event performance, while people who had different motivations for being at the destination may have been surprised by the EE. 


\section{Theoretical implications}

From a theoretical perspective, this paper enriches the existing event literature in several ways. First, within the context of a mega-event, it not only shows the multidimensionality of event experience and event satisfaction but also proves that event experience is mostly affected by sense and feelings, which underlines the importance of engaging visitors in entertainment activities (Fu et al., 2020; Park and Park, 2017; Van Niekerk, 2017). Second, it is also in line with some previous studies (Fu et al., 2019; Lee et al., 2017; Song et al., 2017; Swart et al., 2018) by showing a positive relationship between positive satisfaction with the event and the destination, which represents a useful contribution to extant event research by bridging visitors' experiential response to an event with destination marketing in a broader context. This result should encourage researchers to further explore how host destinations of events can design experiences to influence future (re)visit intentions and positive word-ofmouth. Third, the study discovers moderating effects, which is a novel finding in sports mega-event studies, providing valuable insights for designing customized visitor experiences. The significance of this study is also demonstrated by the proposal model to test a long-term legacy. Overall, this research offers interesting implications for destinations by demonstrating a trend of visits after an event to show how a mega-sports event may result in more incoming tourist flows and contributes to the existing literature by using a novel legacy model starting from a consumer-based analysis.

\section{Practical implications}

The findings of this paper help tourism destination marketers and managers consider the triggering factors of a satisfying mega-sports event for the host destination and the marketing power of the on-site experience. As demonstrated in this research, mega-events may represent important occasions for destinations to enhance their brand awareness and image by positive word-of-mouth and/or tourists' intentions to return for a vacation. Specifically, for a host destination such as Naples, in April 2012, these goals were more than a tactical tool and rather a strategic marketing signal that the city presented to Italy and worldwide. Therefore, the ACWS represented a first opportunity for a "rebirth" of the local area by reinforcing its many strengths - food, music, culture, art and hospitable people - highlighting the physical, architectural and symbolic potential to foster long-term economic impact. From a long-term perspective, this phenomenon may also drive new tourism demand, increasing tourism and contributing to sustainable economic growth at the destination, particularly if linked to a wider destination strategy.

The empirical evidence from this study demonstrated that a great event experience positively affects the willingness to return and recommend the city for a different reason (e.g., holiday) by confirming an embedded link between event and destination, which helps in planning to manage a mega-event legacy. In the particular case of Naples, the ACWS tourism industry has experienced a considerable boom, and there has certainly been an increase in the number of tourists compared with the "before-event" stage, which could be considered an unplanned event legacy (Preuss, 2007). Moreover, the occupancy rate increased from $42.12 \%$ in 2012 before the event to $64.89 \%$ in 2016 , three years after the event, and to $71.40 \%$ in 2019 . Similarly, incoming demand rose from 2,166,518 tourists in 2012 to 3,292,556 tourists in 2016 (Risitano and Sorrentino, 2018) to 3,700,000 in 2019, and the city was cited by important tourist rating guides (e.g., Lonely Planet, TripAdvisor).

From a demand side, measurement of the event's legacy in terms of tourism increase is still uncertain. It is difficult to identify a causal relationship between event performance and future tourism development, particularly for the intangible legacy related to a renewed destination image and the city's new attractiveness left by the event, which is often part of a wider medium- to long-term destination marketing strategy (Dansero and Puttilli, 2010). 
JHTI 3,5

\section{0}

However, there is reasonable certainty that the event has changed the image of the destination, leading to an increase in tourist flows as well as the opening of accommodation businesses. The city of Naples - and specifically the ACWS venue - has in fact been chosen as the location for national and international events in fashion and cinema and by some multinational companies as the location for the launch campaigns of new products. As shown in Figure 2, incoming tourist flows have almost doubled since the event.

Destination marketers are encouraged to continue sharing intangible assets, such as event-related news or stories, on social media and construct a good atmosphere in the online community. These efforts maintain the interests and attention of tourists at the events and at the destination, potentially increasing their revisit intentions during the next event. Destinations should manage the local tourism industry before, during and after hosted megaevents to better understand the impact on local development. A possible test to measure this legacy should be conducted in a longitudinal multilevel perspective (see Figure 3): individual, industry and destination levels. To capture the impact of a mega-event, the multi-item scale should be measured before and immediately after and in the medium and long terms (one and three years).

At the individual level, the model investigates the existing profile of incoming tourist demand (e.g., sociodemographic and behavioral profiles). The industry level measures the tourist offerings (supply side) in terms of the numbers of hotels, attractions, restaurants, entertainment activities and other amenities and tourist flows (demand side) in terms of arrivals, presences and average length of stay. At the destination level, items monitor the numbers of sports events, other large-scale events and citations of the destination related and not related to the event. Finally, the model employs a moderator variable to consider in the interpretation of results. The presence (or not) of a planned destination marketing strategy could represent a crucial factor for reducing or enhancing the trigger role of the event in the future destination development.

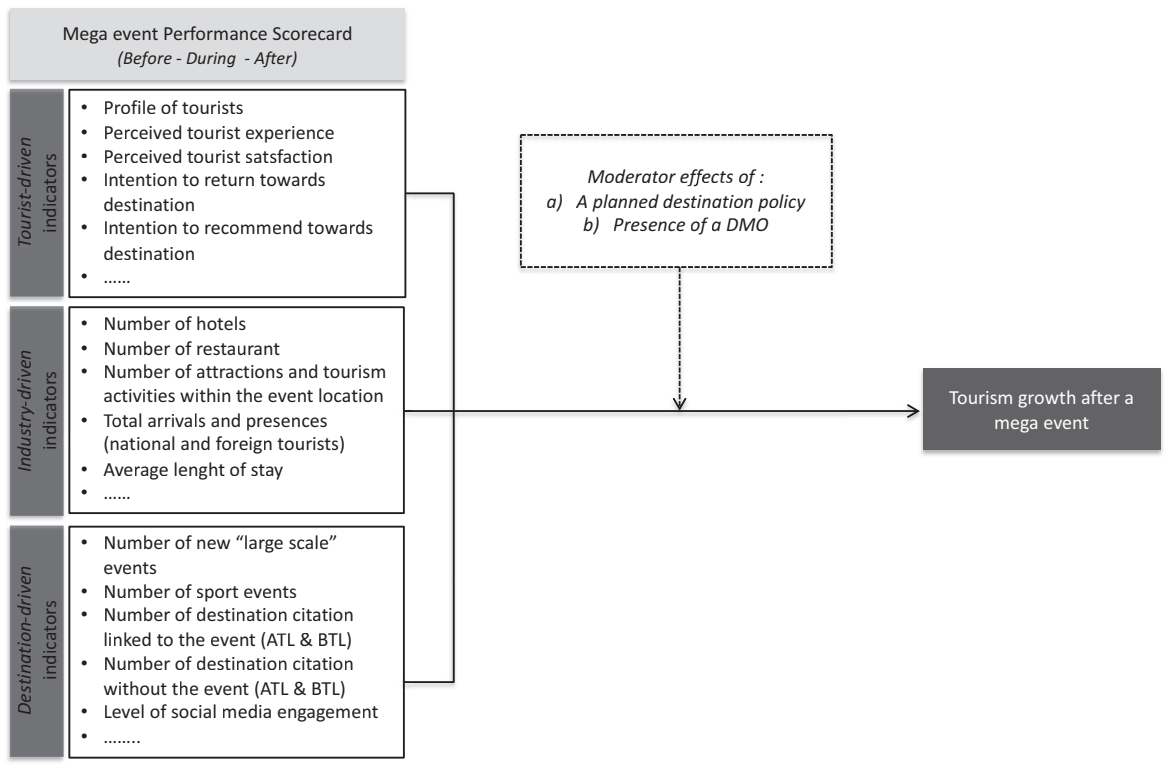

Figure 2.

Toward a longitudinal multilevel model of mega-event tourism legacy 


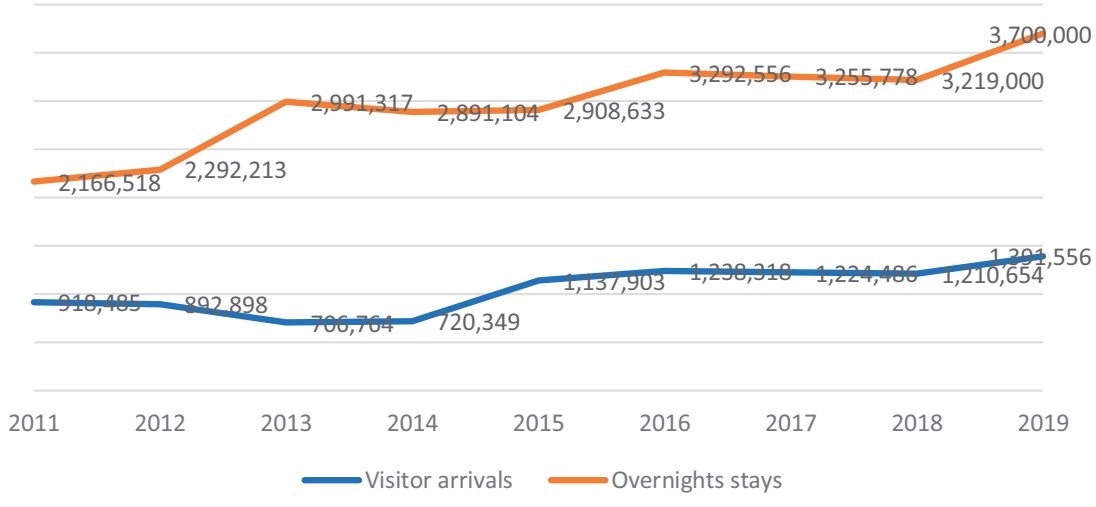

Source(s): our elaboration
Measuring event experience

\section{Limitations and research opportunities}

This study has shed light on several important issues. Nevertheless, it had some limitations. First, the convenience sampling method means that the results cannot necessarily be generalized. Second, the nationality of the respondents was assigned by their place of residence, but it would be interesting to conduct an analysis of national culture. Third, the event legacy in terms of the destination image and incoming tourism development was not directly measured. Future studies could use qualitative methods to interview policymakers and local entrepreneurs about how a mega-event influenced tourist growth. Moreover, it could be interesting to compare similar sports mega-events and the long-term effects of new tourism on the host destination, while employing an empirical test of the proposed measurement scale.

\section{References}

Alcántara-Pilar, J.M., del Barrio-García, S., Crespo-Almendros, E. and Porcu, L. (2017), "Toward an understanding of online information processing in e-tourism: does national culture matter?", Journal of Travel and Tourism Marketing, Vol. 34 No. 8, pp. 1128-1142.

Ali, F., Hussain, K. and Omar, R. (2016), "Diagnosing customers experience, emotions and satisfaction in Malaysian resort hotels", European Journal of Tourism Research, Vol. 12 No. 1, pp. 25-40.

Ali, F., Kim, W.G., Li, J.J. and Cobanoglu, C. (2018), "A comparative study of covariance and partial least squares based structural equation modelling in hospitality and tourism research", International Journal of Contemporary Hospitality Management, Vol. 30 No. 1, pp. 416-435.

Arnegger, J. and Herz, M. (2016), "Economic and destination image impacts of mega-events in emerging tourist destinations", Journal of Destination Marketing and Management, Vol. 5 No. 2, pp. 76-85.

Ayob, N., Wahid, N.A. and Omar, A. (2013), "Mediating effect of visitors' event experiences in relation to event features and post-consumption behaviours", Journal of Convention and Event Tourism, Vol. 14 No. 3, pp. 177-192.

Barclay, D., Higgins, C. and Thompson, R. (1995), "The partial least squares (PLS) approach to causal modeling: personal computer adoption and use as an illustration”, Technology Studies, Vol. 2 No. 2, pp. 285-309.

Berridge, G. (2007), Events Design and Experience, Routledge, London. 
JHTI

3,5

602

Bigne, J.E., Sanchez, M.I. and Sanchez, J. (2001), "Tourism image, evaluation variables and after purchase behaviour: inter-relationship", Tourism Management, Vol. 22 No. 6, pp. 607-616.

Brakus, J.J., Schmitt, B.H. and Zarantonello, L. (2009), "Brand experience: what is it? How is it measured? Does it affect loyalty?", Journal of Marketing, Vol. 73 No. 3, pp. 52-68.

Brown, G., Smith, A. and Assaker, G. (2016), "Revisiting the host city: an empirical examination of sport involvement, place attachment, event satisfaction and spectator intentions at the London Olympics", Tourism Management, Vol. 55 No. 2, pp. 160-172.

Caro, L.M. and García, J.A.M. (2007), "Cognitive-affective model of consumer satisfaction. An exploratory study within the framework of a sporting even”, Journal of Business Research, Vol. 60 No. 2, pp. 108-114.

Chalip, L. and Fairley, S. (2019), "Thinking strategically about sport events", Journal of Sport and Tourism, Vol. 23 No. 4, pp. 155-158.

Chalip, L., Green, C. and Hill, B. (2003), "Effects of sport event media on destination image and intention to visit", Journal of Sport Management, Vol. 17 No. 2, pp. 214-234.

Chand, M. and Kumar, S. (2017), "Investigating holiday satisfaction of Chinese and Japanese tourists visiting India", International Journal of Hospitality and Tourism Systems, Vol. 10 No. 2, pp. 68-78.

Chang, L.L., Backman, F., Chih and Huang, Y. (2014), "Creative tourism: a preliminary examination of creative tourists' motivation, experience, perceived value and revisit intention", International Journal of Culture, Tourism and Hospitality Research, Vol. 8 No. 4, pp. 401-419.

Chen, N. and Funk, D.C. (2010), "Exploring destination image, experience and revisit intention: a comparison of sport and non-sport tourist perceptions", Journal of Sport and Tourism, Vol. 15 No. 1, pp. 239-259.

Chiu, Y.B., Lin, C.P. and Tang, L.L. (2005), "Gender differs: assessing a model of online purchase intentions in e-tail service", International Journal of Service Industry Management, Vol. 16 No. 5, pp. 416-435.

Coghlan, A. and Filo, K. (2016), "Bringing personal character strengths into the production of the leisure experience”, Leisure Sciences, Vol. 38 No. 2, pp. 100-117.

Crotts, J.C. (2004), "The effect of cultural distance on overseas travel behaviors", Journal of Travel Research, Vol. 43 No. 1, pp. 83-88.

Dansero, E. and Puttilli, M. (2010), "Mega-events tourism legacies: the case of the Torino 2006 Winter Olympic Games-a territorialisation approach”, Leisure Studies, Vol. 29 No. 3, pp. 321-341.

Del Bosque, I.R. and Martín, H.S. (2008), "Tourist satisfaction a cognitive-affective model”, Annals of Tourism Research, Vol. 35 No. 2, pp. 551-573.

Dibbern, J. and Chin, W.W. (2010), “An introduction to a permutation-based procedure for multi-group pls analysis: results of tests of differences on simulated data and a cross cultural analysis of the sourcing of information system services between Germany and the USA", Handbook of Partial Least Squares: Concepts, Methods and Applications, pp. 171-193.

Dos Santos, M.A. (2012), "An attendance behavior model at sports events: comparison and constrast of two models”, Sport Science Review, Vol. 21 No. 2, pp. 21-36.

Dos Santos, M.A., Baeza, S. and Lizama, J.C. (2019), "The intention of attending a sporting event through expectation disconfirmation and the effect of emotions", Integrated Marketing Communications, Strategies, and Tactical Operations in Sports Organizations, IGI Global, Hershey, PA, pp. 223-240.

Downward, P., Lumsdon, L. and Ralston, R. (2005), "Gender differences in sports event volunteering: insights from crew 2002 at the XVII Commonwealth Games", Managing Leisure, Vol. 10 No. 4, pp. 219-236. 
Fu, X., Kang, J., Hahm, J. and Wiitala, J. (2020), "Investigating the consequences of theme park experience through the lenses of self-congruity and flow", International Journal of Contemporary Hospitality Management, Vol. 32 No. 3, pp. 1181-1199.

$\mathrm{Fu}, \mathrm{X}$., Yi, X., Okumus, F. and Jin, W. (2019), "Linking the internal mechanism of exhibition attachment to exhibition satisfaction: a comparison of first-time and repeat attendees", Tourism Management, Vol. 72, pp. 92-104.

Getz, D. (2008), "Event tourism: definition, evolution, and research", Tourism Management, Vol. 29 No. 3, pp. 403-428.

Giampiccoli, A., Lee, S.S. and Nauright, J. (2015), "Destination South Africa: comparing global sports mega-events and recurring localised sports events in South Africa for tourism and economic development", Current Issues in Tourism, Vol. 18 No. 3, pp. 229-248.

Hair, J.F. Jr, Hult, G.T.M., Ringle, C. and Sarstedt, M. (2016), A Primer on Partial Least Squares Structural Equation Modeling (PLS-SEM), Sage Publications, New York.

Hansen, T. and Møller Jensen, J. (2009), "Shopping orientation and online clothing purchases: the role of gender and purchase situation", European Journal of Marketing, Vol. 43 No. 9, pp. 1154-1170.

Hofstede, G. (1980), "Motivation, leadership, and organization: do American theories apply abroad?", Organizational Dynamics, Vol. 9 No. 1, pp. 42-63.

Hofstede, G. (2001), Culture's Consequences: Comparing Values, Behaviors, Institutions, and Organizations across Nations, 2nd ed., Sage, London.

Huang, L. (2017), "Birds of a feather: a normative model of assessing consumers' satisfaction in a generalized expectation-disconfirmation paradigm", Journal of Marketing Analytics, Vol. 5 No. 1, pp. 5-13.

Hui, T.K., Wan, D. and Ho, A. (2007), "Tourists' satisfaction, recommendation and revisiting Singapore", Tourism Management, Vol. 28 No. 4, pp. 965-975.

Jones, R.J., Reilly, T.M., Cox, M.Z. and Cole, B.M. (2017), “Gender makes a difference: investigating consumer purchasing behavior and attitudes toward corporate social responsibility policies", Corporate Social Responsibility and Environmental Management, Vol. 24 No. 2, pp. 133-144.

Jöreskog, K.G. (1978), "Structural analysis of covariance and correlation matrices", Psychometrika, Vol. 43 No. 4, pp. 443-477.

Kaplanidou, K. and Gibson, H.J. (2010), "Predicting behavioral intentions of active event sport tourists: the case of a small-scale recurring sports event”, Journal of Sport and Tourism, Vol. 15 No. 2, pp. 163-179.

Kaplanidou, K. and Vogt, C. (2007), "The interrelationship between sport event destination image and sport tourists' behaviors", Journal of Sport and Tourism, Vol. 12 No. 2, pp. 183-206.

Kaplanidou, K. and Vogt, C. (2010), "The meaning and measurement of a sport event experience among active sport tourists”, Journal of Sport Management, Vol. 12 No. 3, pp. 544-566.

Kaplanidou, K.K., Jordan, J.S., Funk, D. and Ridinger, L.L. (2012), "Recurring sport events and destination image perceptions: impact on active sport tourist behavioural intentions and place attachment", Journal of Sport Management, Vol. 26 No. 1, pp. 237-248.

Kaplanidou, K. (2009), "Relationships among behavioral intentions, cognitive event and destination images among different geographic regions of Olympic Games spectators", Journal of Sport and Tourism, Vol. 14 No. 4, pp. 249-272.

Kim, S. and McKercher, B. (2011), "The collective effect of national culture \& tourist culture on tourist behavior", Journal of Travel and Tourism Marketing, Vol. 28 No. 2, pp. 145-164.

Kim, J.H., Ritchie, J.B. and McCormick, B. (2012), "Development of a scale to measure memorable tourism experiences", Journal of Travel Research, Vol. 51 No. 1, pp. 12-25. 
JHTI 3,5

Kim, J.S., Song, H., Lee, C.K. and Lee, J.Y. (2017), "The impact of four CSR dimensions on a gaming company's image and customers' revisit intentions", International Journal of Hospitality Management, Vol. 61 No. 3, pp. 73-81.

Knott, B., Fyall, A. and Jones, I. (2017), "Sport mega-events and nation branding”, International Journal of Contemporary Hospitality Management, Vol. 29 No. 3, pp. 900-923.

Kotler, P. and Keller, K.L. (2001), A Framework for Marketing Management, Vol. 2, Prentice Hall, Upper Saddle River, NJ.

Kozak, M. (2003), "Measuring tourist satisfaction with multiple destination attributes", Tourism Analysis, Vol. 7 No. 3, pp. 229-240.

Lee, J.S., Lee, C.K. and Choi, Y. (2011), "Examining the role of emotional and functional values in festival evaluation", Journal of Travel Research, Vol. 50 No. 2, pp. 685-696.

Lee, W., Sung, H., Suh, E. and Zhao, J. (2017), “The effects of festival attendees' experiential values and satisfaction on re-visit intention to the destination: the case of a food and wine festival", International Journal of Contemporary Hospitality Management, Vol. 29 No. 3, pp. 1005-1027.

Lucey, B.M. and Zhang, Q. (2010), "Does cultural distance matter in international stock market comovement? Evidence from emerging economies around the world", Emerging Markets Review, Vol. 11 No. 1, pp. 62-78.

Müller, M. (2015), "What makes an event a mega-event? Definitions and sizes”, Leisure Studies, Vol. 34 No. 6, pp. 627-642.

Ng, S.I., Lee, J.A. and Soutar, G.N. (2007), “Tourists' intention to visit a country: the impact of cultural distance", Tourism Management, Vol. 28 No. 6, pp. 1497-1506.

Nicolau, J.L. and Mas, F.J. (2006), "The influence of distance and prices on the choice of tourist destinations: the moderating role of motivations", Tourism Management, Vol. 27 No. 5, pp. 982-996.

Novelli, M., Schmitz, B. and Spencer, T. (2006), "Networks, clusters and innovation in tourism: a UK experience", Tourism Management, Vol. 27 No. 3, pp. 1141-1152.

Nunnally, J.C. and Bernstein, I.H. (1994), "The assessment of reliability", Psychometric theory, Vol. 3 No. 1, pp. 248-292.

Okazaki, S. and Mendez, F. (2013), "Exploring convenience in mobile commerce: moderating effects of gender", Computers in Human Behavior, Vol. 29 No. 3, pp. 1234-1242.

Park, S.B. and Park, K. (2017), "Thematic trends in event management research", International Journal of Contemporary Hospitality Management, Vol. 29 No. 3, pp. 848-861.

Pizam, A. and Sussman, S. (1995), "Does nationality affect tourist behavior?", Annals of Tourism Research, Vol. 22 No. 2, pp. 901-917.

Prayag, G. and Grivel, E. (2014), "Motivation, satisfaction, and behavioural intentions: segmenting youth participants at the Interamnia World Cup 2012", Sport Marketing Quarterly, Vol. 23 No. 3, pp. 148-160.

Preuss, H. (2007), "The conceptualisation and measurement of mega sport event legacies", Journal of Sport and Tourism, Vol. 12 No. 3, pp. 207-228.

Risitano, M. and Sorrentino, A. (2018), Strategie di marketing dei territori e ruolo dei mega eventi. Il caso Napoli, Giappichelli, Torino.

Risitano, M., Romano, R., Sorrentino, A. and Quintano, M. (2017a), "Evaluating tourist behaviour in sport mega-events through a structural equation model", Mercati and Competitività, No. 3, pp. 101-126.

Risitano, M., Tutore, I., Sorrentino, A. and Quintano, M. (2017b), “The influence of tourists' national culture on their behaviors in a sport mega-event", International Journal of Culture, Tourism and Hospitality Research, Vol. 11 No. 2, pp. 193-210. 
Sarstedt, M., Henseler, J. and Ringle, C.M. (2011), "Multigroup analysis in partial least squares (PLS) path modeling: alternative methods and empirical results", Measurement and Research Methods in International Marketing, pp. 195-218.

Song, H.J., Ahn, Y.J. and Lee, C.K. (2015), "Structural relationships among strategic experiential modules, emotion and satisfaction at the Expo 2012 Yeosu Korea", International Journal of Tourism Research, Vol. 17 No. 3, pp. 239-248.

Song, H.J., Bae, S.Y. and Lee, C.-K. (2017), "Identifying antecedents and outcomes of festival satisfaction: the case of a cosmetics \& beauty expo", International Journal of Contemporary Hospitality Management, Vol. 29 No. 3, pp. 947-965.

Song, H., Kim, M. and Choe, Y. (2019), "Structural relationships among mega-event experiences, emotional responses, and satisfaction: focused on the 2014 Incheon Asian Games", Current Issues in Tourism, Vol. 22 No. 5, pp. 575-581.

Swart, K., George, R., Cassar, J. and Sneyd, C. (2018), "The 2014 FIFA World Cup ${ }^{\mathrm{TM}}$ : tourists' satisfaction levels and likelihood of repeat visitation to Rio de Janeiro", Journal of Destination Marketing and Management, Vol. 8 No. 3, pp. 102-113.

Tung, V.W.S. and Ritchie, J.R. (2011), "Exploring the essence of memorable tourism experiences", Annals of Tourism Research, Vol. 38 No. 4, pp. 1367-1386.

Van Niekerk, M. (2017), "Contemporary issues in events, festivals and destination management", International Journal of Contemporary Hospitality Management, Vol. 29 No. 3, pp. 842-847.

Weed, M. (2005), "Sports tourism theory and method-concepts, issues and epistemologies", European Sport Management Quarterly, Vol. 5 No. 3, pp. 229-242.

Wetzels, M., Odekerken-Schröder, G. and Van Oppen, C. (2009), "Using PLS path modeling for assessing hierarchical construct models: guidelines and empirical illustration”, MIS Quarterly, Vol. 33 No. 1, pp. 177-195.

Wold, H. (1985), "Partial least squares", in Kotz, S. and Johnson, N.L. (Eds), Encyclopedia of Statistical Sciences, Vol. 6, John Wiley, New York, pp. 581-891.

Yang, J., Gu, Y. and Cen, J. (2014), "Festival tourists' emotion, perceived value, and behavioral intentions: a test of the moderating effect of festivalscape", Journal of Convention and Event Tourism, Vol. 12 No. 1, pp. 25-44.

Yang, Y., Liu, H., Li, X.R. and Harrill, R. (2018), "A shrinking world for tourists? Examining the changing role of distance factors in understanding destination choices", Journal of Business Research, Vol. 92 No. 3, pp. 350-359.

Zarantonello, L., Schmitt, B. and Brakus, J.J. (2007), "Development of the brand experience scale”, ACR North American Advances, Vol. 34 No. 1, pp. 580-582.

\section{Corresponding author}

Annarita Sorrentino can be contacted at: annarita.sorrentino@uniparthenope.it

For instructions on how to order reprints of this article, please visit our website:

www.emeraldgrouppublishing.com/licensing/reprints.htm

Or contact us for further details: permissions@emeraldinsight.com 